
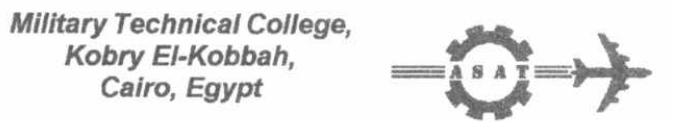

$9^{\text {th }}$ International Conference

On Aerospace Sciences \&

Aviation Technology

\title{
Effect of Different Parameters on the Drag Coefficient for Commercial Vehicles
}

\author{
Abdel Azim* A. F. and Abdel Gawad** A. F.
}

\begin{abstract}
Large commercial vehicles (e.g. truck-trailer combination), due to their function, are bluff bodies by nature. The truck-trailer combination usually gives a drag coefficient that is less than that for a trailer alone. The interference between the commercial vehicles and other small vehicles is of primary importance especially when moving in driving tunnels that are characterized by their limited space. 1/19-scale models for commercial vehicles are employed in the experimental work performed here. Three-dimensional pressure measurements are recorded for analyzing the aerodynamic behavior and calculating the drag coefficient. Add-on devices (deflectors) are used. Measurements are supported by both numerical calculations and flow visualization. Results show that add-on devices play a very important role in improving the aerodynamic characteristics of commercial vehicles.
\end{abstract}

\section{KEY WORDS}

Aerodynamics, Commercial Vehicles, Deflectors, Overtaking, Driving Tunnels, and Drag

\footnotetext{
* Chairman, Mechanical Power Engineering Dpt., Faculty of Engineering, Zagazig University, Zagazig, Egypt.

** Assistant Professor, Mechanical Power Engineering Dpt., Faculty of Engineering. Zagazig University, Zagazig, Egypt .
} 


\section{NOMENCLATURE}

$\begin{array}{ll}A_{i} & \text { Projected area } \\ C_{D} & \text { Drag coefficient } \\ C_{p} & \text { Pressure coefficient } \\ H_{c} & \text { Height of the truck cab } \\ H_{L} & \text { Height of the truck load } \\ L_{g s} & \text { Side gab between the two interfering vehicles } \\ P & \text { Static pressure } \\ P_{\infty} & \text { Freestream pressure } \\ U_{\infty} & \text { Freestream mean velocity } \\ W_{N} & \text { Width of the Nissan pickup } \\ \Phi & \text { Velocity potential } \\ \rho & \text { Air density }\end{array}$

\section{INTRODUCTION}

Escalating fuel prices and the need for profitable operation encourage the commercial vehicle manufacturers to exploit all opportunities for minimizing fuel consumption. One such opportunity is aerodynamic efficiency. High-bodied commercial vehicles, touring coaches and delivery vans are therefore the targets for improved aerodynamic design to reduce fuel consumption [9]. The large commercial vehicles, due to their function, have tended to be relatively unstreamlined and typically their shape is one bluff body (the cab) in front of a larger bluff body (the trailer). This geometry usually gives a drag for the tandem combination that is less than the drag of the trailer alone. To further reduce the drag and fuel consumption, their shapes are frequently modified, consistent with keeping a maximum loading capacity in the trailer. One of the methods that have traditionally been used is the deflector-type device mounted on the cab. The deflector devices are sized and positioned such that their wake is just large enough to envelop the front face of the trailer, giving mutually beneficial drag reductions and thus lowering total vehicle drag [15]. Deflectors take different shapes and sizes depending on the size and gross load of the tractor-trailer. The first author ([1], [2], [3] and [4]) performed an extensive research work concerning the aerodynamics of commercial vehicles. Kong and Parkinson [10] tested the pressure distribution on three models of large truck-trailer combinations. Tests were carried out in a passive form of blockage-tolerant wind tunnel designed for wind engineering model testing. The test section provides low blockage corrections for the test models by a sequence of uniformly spaced ring airfoils replacing the usual sidewalls and ceiling. These are surrounded by an annular plenum. A solid floor forms a chord of the circular cross section and represents the ground. The results indicate that pressure distributions and drag coefficients are unaffected by blockage for values as high as $29 \%$. Abdel Azim [5] made an experimental study of the aerodynamic interference between a truck and a semi-trailer. He used 1/10-scale models for a static type testing. Different relative longitudinal and lateral positions were examined. He 
stated that the side force and yawing moment of the trailer about the hitch point of the semi-trailer leads to its turn around the hitch point. Consequently, the safety and stability of the nearby vehicles are critically influenced. Watkins et al. [15] made a comparison between road and wind tunnel drag reductions due to streamlining devices for commercial vehicles. They used two types of streamlining devices, namely: small deflectors and large streamlined fairing. Comparison of drag coefficient reductions, at high yaw angles, shows that road results are considerably lower than tunnel results. Whereas, at low yaw angles the road drag reductions can be higher than those measured in the tunnel. However, tunnel data obtained in grid-generated turbulence are closer to the results obtained on the road under high yaw angles. Olson and Schaub [12] carried out an experimental comparison between two half-size truck models with variable length, grain-haul height, closed trailers, and with identical frontal areas and length/volume distributions. One of the models was a simple block. Whereas, the second model accurately replicated body shape and hardware exposed to external and cooling air streams. Testing was conducted in a $9 \mathrm{~m} \times 9 \mathrm{~m}$-wind tunnel over a velocity range of 48 to $193 \mathrm{kph}$. Both models were yawed through $\pm 14^{\circ}$ with full-length and truncated trailer bodies. Their results showed that the accurate reproduction of hardware detail seems to be most important on short-bodied vehicles. Therefore it would seem necessary to model hardware detail with much greater accuracy for short vehicles, such as passenger cars or vans, than for long-bodied vehicles typified by long highway vehicles and trains. Telionis et al. [14] carried out an experimental research to investigate the interference forces between two vehicles (passenger cars and articulated trucks). Tests were conducted in a towing tank and wind tunnels. They stated that the critical area is in the neighborhood of the front of the truck cabin for both parallel passing and opposite crossing. Overshoots of the aerodynamic force components by $50-100 \%$ are encountered in very short periods of time. Their study prevailed clearly the need to investigate the interference and stability of lighter vehicles thoroughly before their construction and marketing are permitted.

The present work represents an experimental study of the effect of different parameters on the drag coefficient of commercial vehicles during its motion through tunnels. These parameters include deflectors and vehicles interference. Two types of deflectors are used. The models of the vehicles are $1 / 19$ of the actual size. The dimensions of the cross-section of the tunnel model are based on El-Galaa underground tunnel, Cairo, Egypt. Results cover distributions of pressure coefficient $\left(C_{p}\right)$, values of drag coefficient at different arrangements of deflectors and interference positions. The experimental results are compared with numerical predictions. The numerical results are obtained using the panel technique to simulate the body of the vehicle. Flow visualization, using a smoke tunnel, is carried out to further understanding the aerodynamic characteristics.

\section{EXPERIMENTAL LAYOUT}

The experiments were performed in the open-circuit, subsonic wind tunnel of the Fluid Mechanics Laboratory, Faculty of Eng., Zagazig Univ., Zagazig, Egypt. A 5.5 kW-3 phase motor, driving an axial fan that rotates at $2855 \mathrm{rpm}$, powers the tunnel. This rotating speed guarantees an average mean velocity of $21.5 \mathrm{~m} / \mathrm{s}(76 \mathrm{~km} / \mathrm{hr})$ within the 
test section. The test section has a length of $2.5 \mathrm{~m}$ and a cross-section of $0.68 \times 0.20 \mathrm{~m}^{2}$ (Fig. 1). As the test section represents a driving tunnel, no blockage correction is needed. Usually, there are two ways to simulate the actual passing (overtaking) process between two vehicles in laboratory [5], namely: static or dynamic testing. When adopting a dynamic test, one vehicle is held stationary while the other is moving. A moving belt may be employed to achieve such relative motion between the two vehicles. Concerning the static testing, the overtaking process is treated in incremental steps. The continuous unsteady overtaking process between two vehicles is replaced by a finite number of steps. The relative position, of both vehicles, changes in each step. This static testing was adopted for the different cases studied in the present investigation.

\section{MODELS AND MEASUREMENTS}

All vehicle models were made from wood, and simulation of very fine details was not attempted. The models, 1/19-scale, were constructed to simulate the geometrical configurations of the actual vehicles so that general aerodynamic trends could be investigated. Fig. 2a shows the overall dimensions of the tractor of a semi-trailer Hyundai H391-TA-A1. The tractor and trailer models have 110 and 417 pressure taps, respectively. The taps are distributed along the centerline (line 2 ), side lines (1 and 3 ), Fig. $3 a$, and side surfaces, Fig. 3b. Fig. 3c shows the taps distribution along the centerline (line 2). Fig. $2 b$ shows the overall dimensions of a truck Mercedes $3838 / 6$ X 4 . The model of the truck has 114 pressure taps, to measure the pressure distribution in a three-dimensional manner. The distribution of taps along the centerline is shown in Fig. $4 a$. Fig. $2 c$ illustrates the overall dimensions of a pickup Nissan (double cabinet). The model has 110 pressure taps distributed on all the surfaces. The distribution of taps along the centerline is shown in Fig. 5a. In Fig. 2, the real dimensions are shown. For all models, the pressure taps were connected to a micro-manometer via plastic tubes. The connecting tubes were led out of each model in several bundles at its base. Generally the pressure taps are concentrated at locations of expected sharp change in pressure. Following the procedures described by Coleman and Steele [6], the uncertainty in measuring the pressure head and dynamic pressure are $1.21 \%$ and $1.24 \%$, respectively.

\section{TEST CASES}

Different arrangements were tested to cover a wide range of the real moving situations of the commercial vehicles. These cases include:

(a) Hyundai semi-trailer, Fig. 3:

1 - without any of the deflectors.

2- with a flat deflector.

3- with a curved deflector.

(b) Mercedes truck, Fig. 4.

(c) Interference between the Hyundai semi-trailer and the Nissan pickup, Fig. 6:

1- Front of the pickup is at the back of the trailer, Fig. 6 a.

2- Middle of the pickup is at the middle of the trailer, Fig. $6 \mathrm{~b}$. 
3- Front of the pickup is at the front of the trailer, Fig. 6c.

4- Front of the pickup is at the front of the tractor, Fig. 6d.

\section{NUMERICAL METHOD}

Many practical flows are closely approximated by the assumption of irrotational, as well as inviscid and incompressible, flow. Thus, the flow governing equations can be reduced to the Laplace equation for the velocity potential:

$\nabla^{2} \Phi=0$

with boundary conditions specifying $\Phi$ or $\partial \Phi / \partial \mathrm{n}$ on all boundaries. Although the finite difference, finite element or spectral methods can solve Eq. 1, more effective methods are available which exploit the possibility of superposing simple exact solutions of Eq. (1) in such a way that the boundary conditions are satisfied. An additional feature of such an approach is that the effective computational domain is the surface of the body rather than the whole region external to the surface (as in the finite difference method). This produces an economical algorithm and permits complicated body shapes to be analyzed with relative ease [7]. These techniques are called panel methods, which are widely used in the aircraft industry ([11] and [4]) and automobile industry [13]. Thus, the panel method is adopted in the present work. The panel method takes its name from the subdivision of the surface of the body into a number of continuous panels (Fig. 7) associated with which are source densities of strength $\sigma_{f}$ to be determined as an intermediate part of the solution process. The distribution of source panels in a uniform stream of velocity $U_{\infty}$ parallel to the x-axis (Fig. 7) produces a potential $\varphi\left(x_{k}, y_{k}\right)$ given by:

$\Phi\left(x_{k}, y_{k}\right)=U_{x} x_{k}+\frac{1}{2 \pi} \sum_{j=1}^{N} \sigma_{j} \int \ln r_{k j} d s_{j}$

where

$r_{k j}=\left[\left(x_{k}-x_{j}\right)^{2}+\left(y_{k}-y_{j}\right)^{2}\right]^{1 / 2}$

$\sigma_{j} \int d s_{j}$ is the source strength of the jth panel. Eq. 2 with 3 , satisfies Eq. 1. The source densities $\sigma_{j}$ are to be chosen to satisfy the boundary condition of no flow through the body surface. The boundary condition of zero normal velocity at the body surface becomes:

$$
\begin{aligned}
v_{n} & =\frac{\partial \Phi}{\partial n_{k}}\left(x_{k}, y_{k}\right) \\
& =-U_{x} \sin \alpha_{k}+\frac{1}{2 \pi} \sum_{j=1}^{N} \sigma_{j} \frac{\partial}{\partial n_{k}}\left(\ln r_{k j}\right) d s_{j}=0
\end{aligned}
$$

where $\alpha_{k}$ is the slope of the body surfaces at the kth control point (typically the midpoint of the kth panel, Fig. 7). Eq. 4 is repeated for each control point producing a linear system of equations:

A $\sigma=R$

where a component of $\underline{A}$ is 
$\mathrm{A}_{\mathrm{kj}}=0.5 \delta_{\mathrm{kj}}+\frac{1}{2 \pi} \int \frac{\partial}{\partial \mathrm{n}_{\mathrm{k}}}\left(\ln \mathrm{r}_{\mathrm{kj}}\right) \mathrm{ds}$,

a component of $\mathrm{R}$ is

$\mathrm{R}_{\mathrm{k}}=\mathrm{U}_{\mathrm{x}} \sin \alpha_{\mathrm{k}}$

and $\sigma$ is the vector of unknown source densities. Once the distribution of source densities is determined, the velocity components due to the presence of the body can be obtained from

$u(x, y)=\frac{1}{2 \pi} \sum_{j=1}^{N} \sigma_{j} \int \frac{x-x_{j}}{\left(x-x_{j}\right)^{2}+\left(y-y_{j}\right)^{2}} d s$,

and

$v(x, y)=\frac{1}{2 \pi} \sum_{j=1}^{N} \sigma_{j} \int \frac{y-y_{j}}{\left(x-x_{j}\right)^{2}+\left(y-y_{j}\right)^{2}} d s$

and the complete velocity field is $q=\left(U_{\infty}+u, v\right)$. Thus, the surface pressure distribution follows directly from the Bernoulli's equation as:

$C_{p}=\frac{p-p_{x}}{0.5 \rho U_{x}^{2}}=1-\left(\frac{q}{U_{x}}\right)^{2}$

Where $P$ and $P_{\infty}$ are the static and freestream pressures, respectively. $\rho$ is the air density and $U_{\infty}$ is the freestream mean velocity. More details are reported in [7]. Here, the panel method is used as a verification tool for the experimental results.

\section{FLOW VISUALIZATION}

Flow patterns of the various test cases were made visible by the smoke technique. The flow visualization was carried out in a smoke tunnel using $1 / 79$-scale models. To trace particles, kerosene was heated and vaporized by an electric heater. The smoke was injected from a raw of small taps. The captured photos help greatly in explaining the experimental results. The visualized flow was captured by a video camera and recorded on videotape. Then the tape was computer-processed to produce the photos.

\section{RESULTS AND DISCUSSIONS}

The experiments were carried out at a Reynolds number of $9.29 \times 10^{5}$ based on air speed and the length of the Hyundai semi-trailer model. The cases of the single Hyundai semi-trailer, the single Mercedes truck, and the single Nissan pickup are considered first. Then, the different interference conditions between the semi-trailer and the pickup are explained.

\section{THE SINGLE HYUNDAI SEMI-TRAILER}

Fig. 8 shows the distribution of the pressure coefficient $\left(C_{0}\right)$ along the circumference of the center section of the semi-trailer. Positive pressure (stagnation) is seen on front of the tractor. Then, a sharp drop $\left(C_{p}=-0.8\right)$ is noticed near the top head of the tractor. 
Pressure recovers again to a positive value at the front of the trailer. Almost a constant negative value $\left(C_{p} \cong-0.1\right)$ appears on most of the top and back surfaces of the semitrailer. Generally, the comparison between the experimental and numerical results is in a good agreement. The distribution of the experimental taps and numerical points are shown in Figs. $3 c$ and $3 d$, respectively. It is worth mentioning that the panel method by its nature is incapable of capturing the actual pressure coefficient in the wake area behind the semi-trailer. The drag coefficient $\left(C_{D}\right)$, found from the experiments, has a value of 0.694. Drag coefficient is defined as: $C_{D}=\frac{\sum_{i} p_{i} A_{i}}{0.5 \rho U_{x}^{2} A} \cdot P_{i}$ and $A_{i}$ are the pressure and projected area of tap i, respectively. $A$ is the total projected area $\left(A=\sum_{i}\right.$ $\left.A_{i}\right)$. This value of 0.694 lies quite in the range of $C_{D}$ mentioned by GÖtz [8] $\left(0.65 \leq C_{D} \leq\right.$ $0.9)$. Two types of deflectors were used to reduce the drag. When using a flat deflector (Fig. 3d) with an inclination of $45^{\circ}$ on the tractor cabinet, the value of $C_{D}$ is 0.623 . This means a drag reduction of $9.97 \%$. Fig. 3e shows the curved deflector fixed on the tractor cabinet. $C_{D}$ becomes 0.55 that represents a drag reduction of $20.5 \%$ (Table 1). So, the use of deflectors has the advantage of significantly reducing the pressure drag and hence reducing fuel consumption.

\section{THE SINGLE MERCEDES TRUCK}

Fig. 9 shows the distribution of $C_{p}$ along the circumference of the center section of the truck. $C_{p}$ values vary between positive values (on the frontal surface of the cabinet and the front windshield) and negative values (on the top surface and along the back window). The numerical results along the centerline are also shown. The distribution of the experimental taps and numerical points are shown in Figs. $4 \mathrm{a}$ and $4 \mathrm{~b}$, respectively. The agreement between the results is good except in the wake areas. The experimental value of the drag coefficient $C_{D}$ is equal to 0.682 . The drag coefficients of both the semi-trailer and the truck are very close to each other. This may be attributed to the similarity between the overall shapes of the truck and the semi-trailer. The comparison between the experimental and numerical results as well as the obtained values of $C_{D}$ gives confidence in the present experimental procedure and results.

\section{THE SINGLE NISSAN PICKUP}

The distribution of the pressure coefficient $\left(C_{\rho}\right)$ along the circumference of the center section of the pickup is shown in Fig. 10. The location of the experimental taps and numerical points are shown in Figs. $5 a$ and $5 b$, respectively. The experimental value of $C_{D}$ is equal to 0.38 . As will be shown later on, the value of $C_{D}$ changes considerably when the pickup overtakes a big commercial vehicle like the Hyundai semi-trailer.

\section{THE PICKUP PASSING THE SEMI-TRAILER}

The relative positions ( $\mathrm{P} 1$ through $\mathrm{P} 4$ ) between the pickup and the semi-trailer are shown in Fig. 6 . The distribution of the pressure coefficient $\left(C_{p}\right)$ along the centerline of the pickup is shown in Fig. 11 for the different relative positions. Table 2 and Fig. 12 
show the variation of the drag coefficient $\left(C_{D}\right)$ of the pickup with the various relative positions. As can be seen, $C_{D}$ drops by about $21 \%$ at position (P1) when the front of the pick up is in line with the back of the semi-trailer. $C_{D}$ increases again at P2 to 0.35 , then decreases to 0.32 . In all positions (P1-P4), the values of $C_{D}$ are less than the value of $C_{D}$ for a single pickup. Fig. 13 shows a comparison between the values of the drag coefficient $\left(C_{D}\right)$, found in the present study, and the values mentioned by GÖtz [8] for the three vehicles tested here.

\section{FLOW VISUALIZATION}

A small model of the truck (1/79-scale) was used to visualize the effects of the deflector, and the size and position of the load on the aerodynamics of the truck. Fig. 14 shows the heights of both the load and cab of the truck. Figs. 15-17 show the side view of the flow field around the truck at different Reynolds numbers. The figures cover the cases of flat and curved deflectors. A strong interaction between the cab and load can be seen. The gap width, measured from the cab rear end to the load front end, and the projecting body height, measured above the cab roof, are essential parameters in this interaction. Streamlines come parallel to the road surface until they approach the cab front surface. They start to deflect to fit the cab-load configuration. When the load is higher than the cab, stagnation at the cab and load fronts is well recognized. Thus, high positive pressure zones, at the front of cab and load, exist (as can be seen in Fig. 9). An increase of the drag force is expected comparing to the case of a load with a height less than the cab height. Flow separates on the roof of the load. Thus, negative pressure at the roof and rear of the vehicle is found. The flow patterns in the cases of the presence of the flat and curved deflectors are shown in Fig. 17. The presence of the deflector reduces the airflow inside the gap between the cab and the load. The streamlines are directed around the front edge of the load. It is found from the present quantitative measurements that the pressure becomes negative on the front surface of the load behind the deflector. Thus, the overall drag coefficient of both the cab and load is reduced. The visualization also reveals the importance of proper setting of the deflector angle. The optimum setting is obtained when the flow doesn't separate on the front edge of the load. Figs. 18-20 show the top view of the truck with different positions of the load on the truck bed. The interaction between the cab and load is well recognized. The photos suggest that the load must be safely secured on the truck bed especially for light loads. Positioning the load at the rear of the truck is the most dangerous situation due to the possibility of forming high positive pressure on the front surface of the load. Thus, the drag on the load increases.

\section{CONCLUSIONS}

The present investigation is an experimental study of the aerodynamic characteristics of commercial vehicles moving in driving tunnels. 1/19-scale models for the commercial vehicles were used. The experimental results were supported by numerical predictions and flow visualization. Based on the shown results and discussions, the following points can be concluded:

1- The results agree with the published data especially for the drag coefficient. 
2- The numerical results give confidence in the present experimental procedure and results.

3- The use of deflectors improves the aerodynamic characteristics of the commercial vehicles and reduces the drag coefficient.

4- An optimum setting of the deflector angle is needed to obtain no separation near the front edge of the roof of the load.

5- The interference between a big commercial vehicle, such as the Hyundai semitrailer, and a small vehicle, such as the Nissan pickup, causes dramatic changes in the value of the drag coefficient $\left(C_{D}\right)$ of the small vehicle. The values of $C_{D}$ for the interfering pickup become significantly less than its value for a single pickup. This means more saving in fuel consumption.

6- Flow visualization is an effective tool in understanding and explaining the flow structure around the commercial vehicles.

Generally, the present study covers the aerodynamic characteristics of several types and sizes of commercial vehicles. The provided data can be used for further experimental and numerical investigations concerning other kinds of add-on devices.

\section{ACKNOWLEDGEMENTS}

The authors would like to express deep thanks to Mr. Hassan E. Hassan and Mr. ElSayed A. El-Sayed for their sincere help.

\section{REFERENCES}

[1] Abdel Azim, A. F., et al., "Use of Air Deflectors and its Effect on Motor Vehicle Fuel Consumptions," Three volumes, Egyptian National Academy contract No. 80/84/6 (1984).

[2] Abdel Azim, A. F., Abdallah, A. Y. and Aly, A. M., "The Aerodynamic Characteristics of a Commercial Truck with Different Loading Configurations," 3rd International Congress of Fluid Mechanics, Cairo, Egypt, Jan. 2-4 (1990a).

[3] Abdallah, A. Y., Abdel Azim, A. F., and Aly, A. M., "The role of Add-on-Devices on the Performance and Aerodynamic Characteristics of Road Vehicles, ${ }^{n}$ 4th Conference on Applied Mechanical Engineering (A. M. E.), Military Technical College, Cairo, Egypt, May 5-7 (1990b).

[4] Abdel Azim, A. F., and Bahbah, M., "Development of a Panel Method for the Study of Two-Dimensional Potential Flow over Single and Two-Element Airfoils," 4th A.S.A.T., Military Technical College, Cairo, Egypt, May 14-16 (1991).

[5] Abdel Azim, A. F., "An Experimental Study of the Aerodynamic Interference between Road Vehicles," SAE International Congress \& Exposition, Detroit, Michigan, Feb. 28 - March 3, paper No. 940422 (1994).

[6] Coleman, H. W., and Steele, W. G., Experimentation and Uncertainty Analysis for Engineers, John Wiley \& Sons, New York (1989).

[7] Fletcher, C. A. J., Computational Techniques for Fluid Dynamics, 2, Springer-Verlag Berlin Heidelberg (1991). 
[8] Götz, H., "Commercial Vehicles," in Aerodynamics of Road Vehicles, ed. by W.-H. Hucho, Butterworths, London (1987).

[9] Hucho, W.-H., Jassen, L. J., and Emmelmann, H.-J., "The Optimization of Body Details-A Method for Reducing the Aerodynamic Drag of Road Vehicles," SAE paper No. 760185 , Detroit (1976).

[10] Kong, L., and Parkinson, G. V., "Road Vehicle Model Testing in a Blockage Tolerant Wind Tunnel," J. Wind Eng. and Industrial Aerodynamics, No. 57, pp. 137143 (1995)

[11] Kraus, W., "Panel Methods in Aerodynamics," in Numerical Methods in Fluid Dynamics, ed. By H. J. Wirz, and J. J. Smolderen, Hemisphere, Washington, D.C., pp. $237-297$ (1978).

[12] Olson, M. E., and Schaub, U. W., "Aerodynamics of Trucks in Wind Tunnels: The Importance of Replicating Model Form, Model Detail, Cooling System and Test Conditions," SAE paper No. 920345 (1992)

[13] Paul, J. C., and LaFond, J. G., "Analysis and Design of Automobile Forebodies Using Potential Flow Theory and a Boundary Layer Separation Criterion," SAE paper No. 830999 (1983).

[14] Telionis, D. P., Fahrner, C. J., And Jones, G. S., "An Experimental Study of Highway Aerodynamic Interferences," J. Wind Eng. And Industrial Aerodynamics, No. 17, pp. 267-293 (1984).

[15] Watkins, S., Saunders, J. W., and Hoffmann, P. H., "Comparison of Road and Wind-Tunnel Drag Reductions for Commercial Vehicles," J. Wind Eng. and Industrial Aerodynamics, No. 49, pp. 411-420 (1993).

Table 1. Drag coefficient $\left(C_{D}\right)$ of the Hyundai semi-trailer

\begin{tabular}{|c|c|c|}
\hline Case & $\mathrm{C}_{D}$ & Drag reduction \\
\hline No deflector & 0.694 & \\
\hline Flat deflector & 0.623 & $9.97 \%$ \\
\hline Curved & 0.55 & $20.5 \%$ \\
\hline
\end{tabular}

Table 2. Drag coefficient $\left(C_{D}\right)$ of the Nissan pickup at different arrangements

\begin{tabular}{|c|c|c|}
\hline Arrangement & $\mathrm{C}_{\mathrm{D}}$ & Drag reduction \\
\hline Single & 0.38 & \\
\hline $\mathrm{P} 1$ & 0.3 & $21 \%$ \\
\hline $\mathrm{P} 2$ & 0.35 & $7.9 \%$ \\
\hline $\mathrm{P} 3$ & 0.32 & $15.8 \%$ \\
\hline $\mathrm{P} 4$ & 0.37 & $2.6 \%$ \\
\hline
\end{tabular}




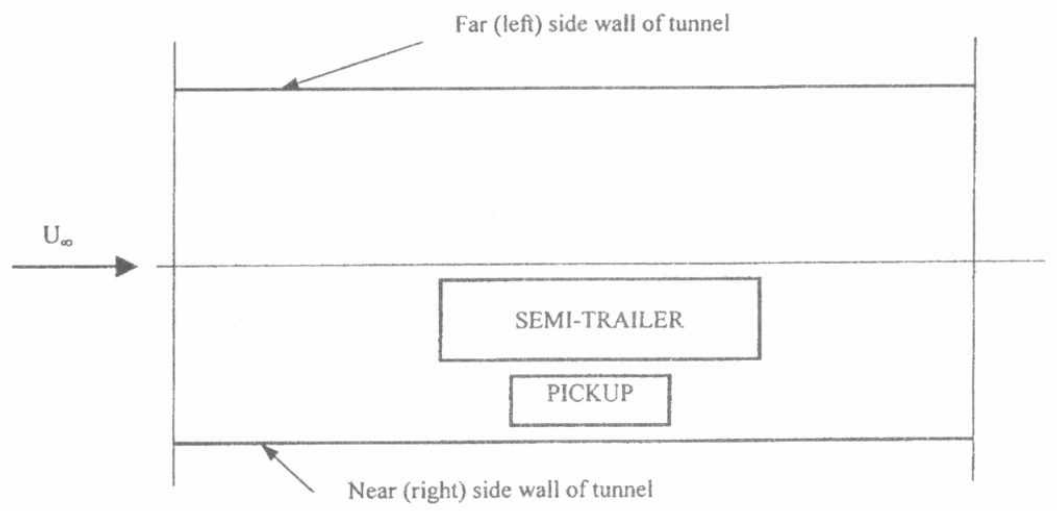

Fig. 1. A top view of the test section.
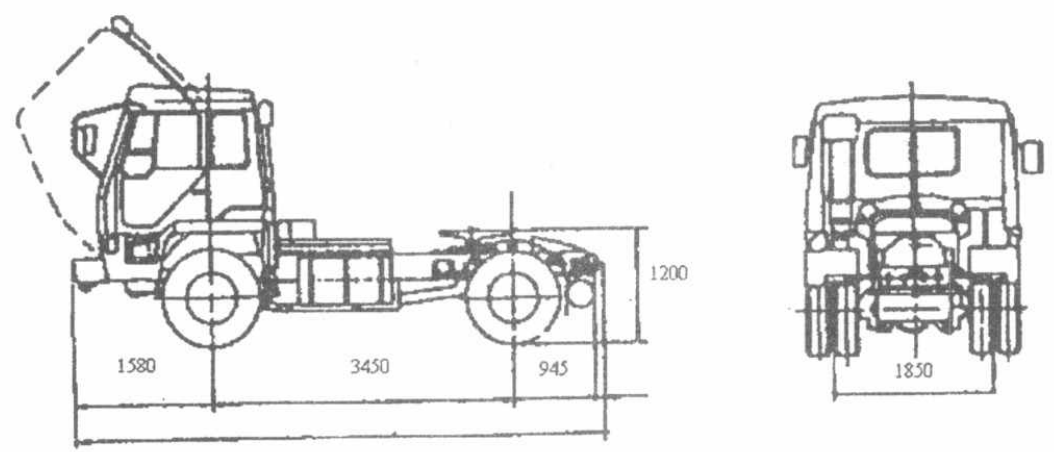

Fig. 2a. The details and overall dimensions of the tractor of the Hyundai semi-trailer. (Dimensions in $\mathrm{mm}$ ) 

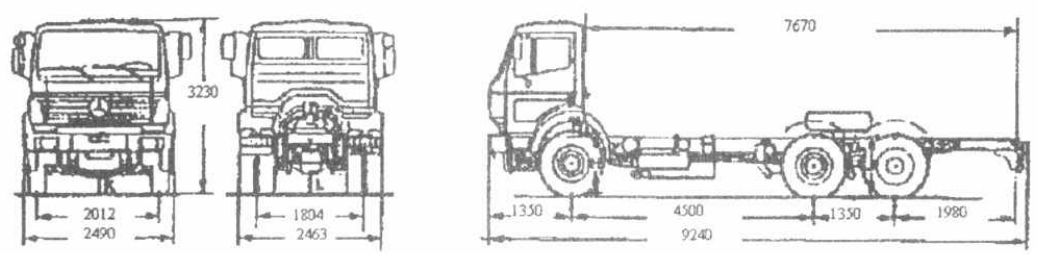

Fig. 2b. The details and overall dimensions of the Mercedes truck.
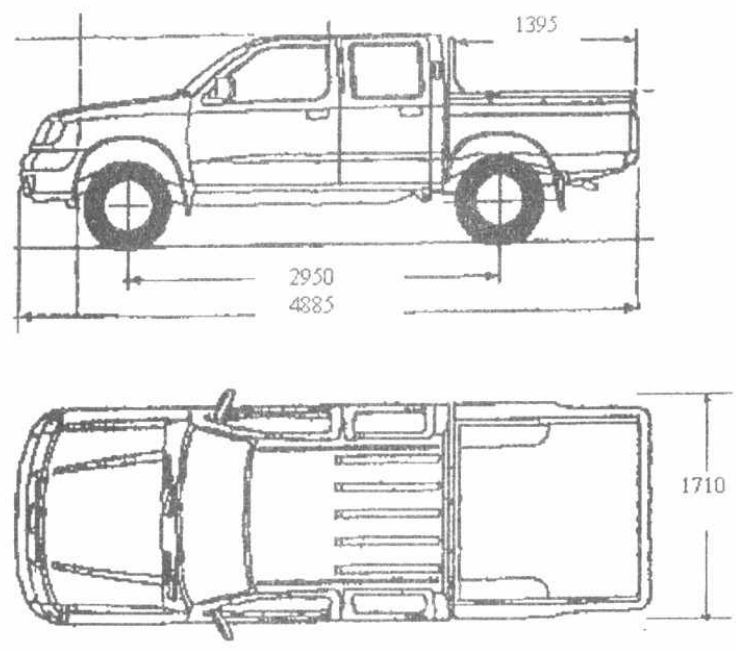

Fig. 2c. The details and overall dimensions of the Nissan pickup

(Dimensions in mm) 


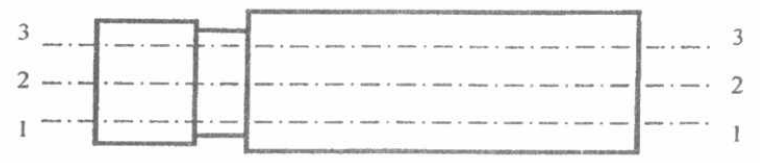

3a. A plan view of the Hyundai semi-trailer.

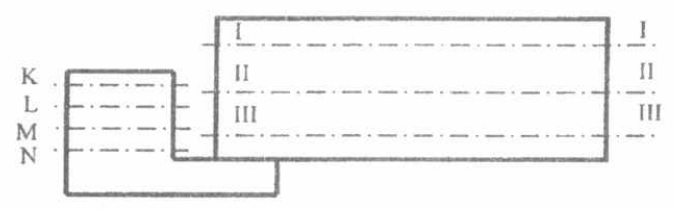

3b. A side view of the Hyundai semi-trailer.

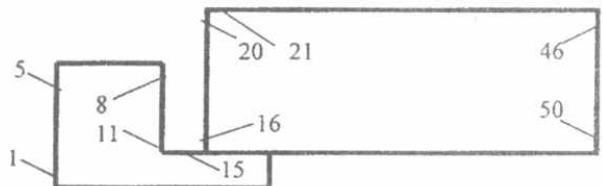

3c. The distribution of experimental taps on the Hyundai semi-trailer.

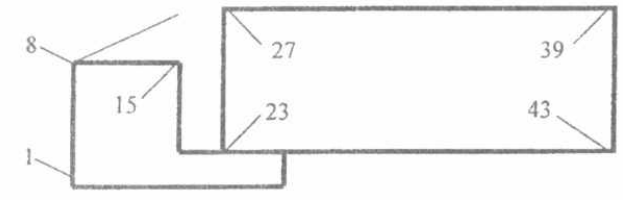

$3 d$. The distribution of the numerical points on the Hyundai semi-trailer with a flat deflector.

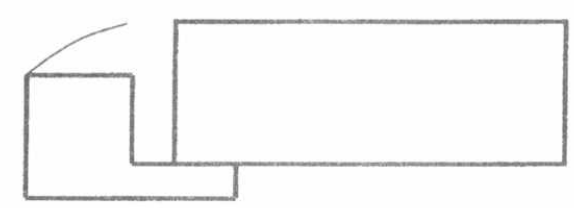

3e. The Hyundai semi-trailer with a curved deflector.

Fig. 3. The Hyundai semi-trailer. 


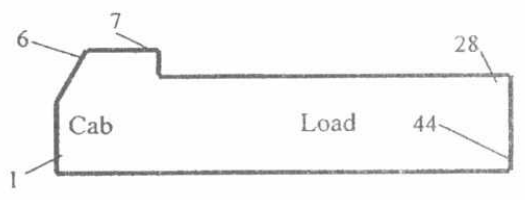

4a. Distribution of experimental taps.

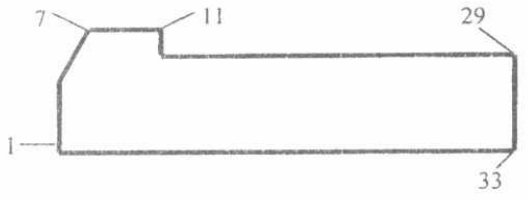

4b. Distribution of the numerical points

Fig. 4. The Mercedes truck

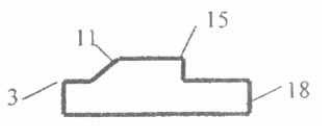

5a. The distribution of experimental taps on the Nissan Pickup.

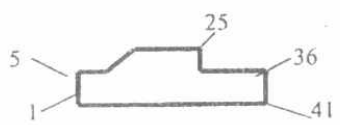

$5 b$. The distribution of the numerical points on the Nissan Pickup.

Fig. 5. The Nissan pickup
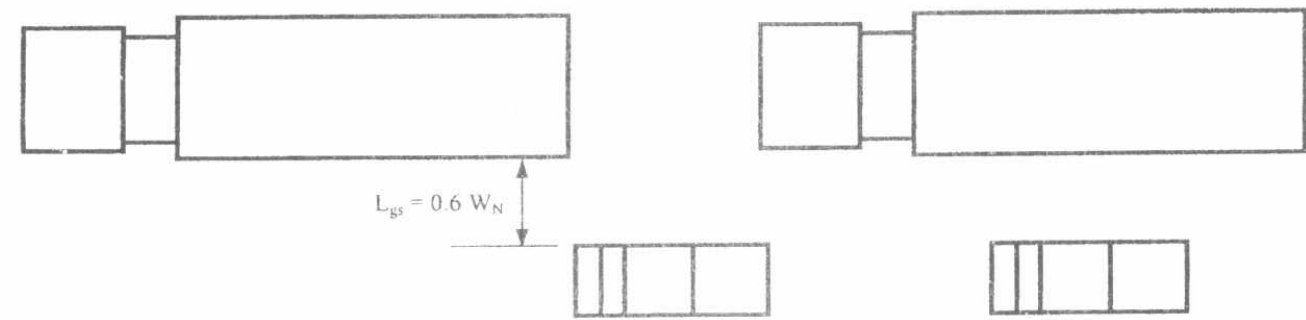

6a. Arrangement (P1)

6b. Arrangement (P2)
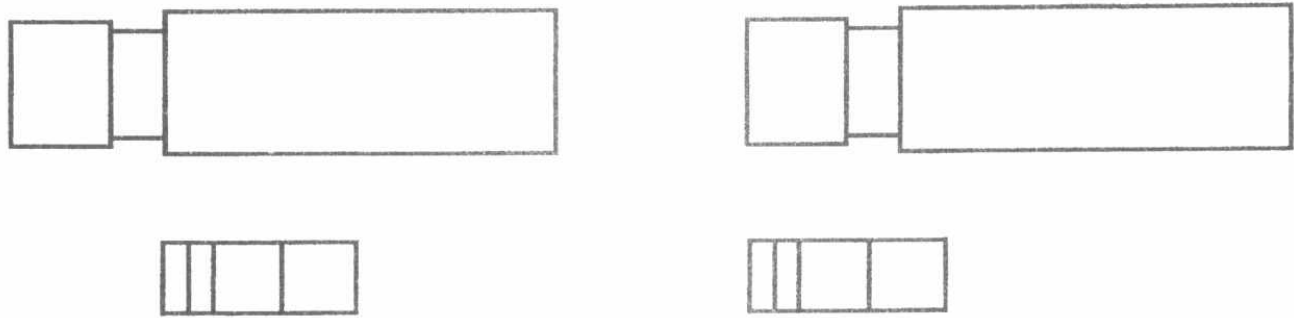

6c. Arrangement (P3)

6d. Arrangement (P4)

Fig. 6. Relative positions between the Hyundai semi-trailer and the Nissan Pickup. 


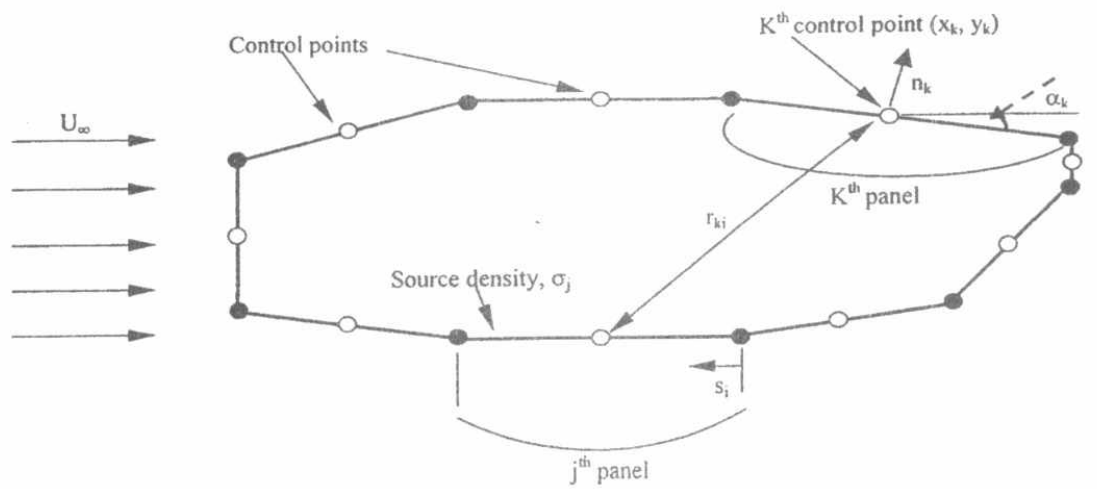

Fig. 7. Panel representation of a body surface.
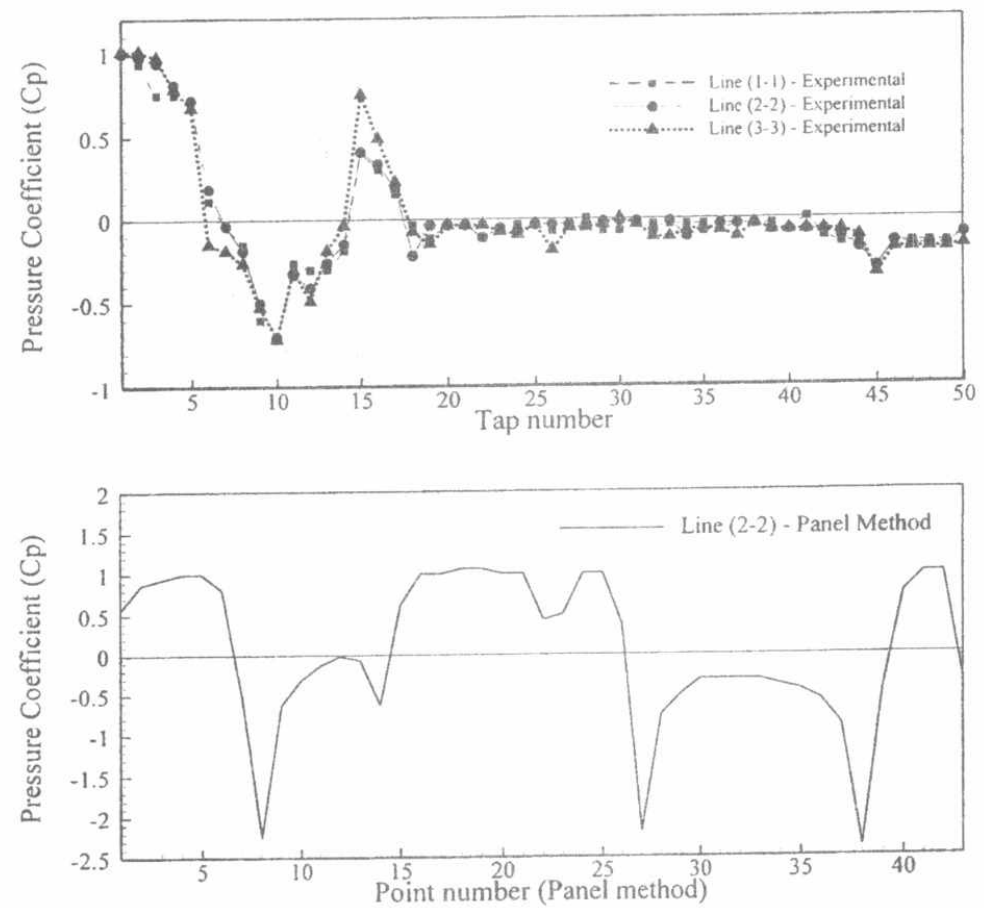

Fig. 8. The distribution of the pressure coefficient $\left(C_{p}\right)$ on the circumference of the center section of the Hyundai semi-trailer. 

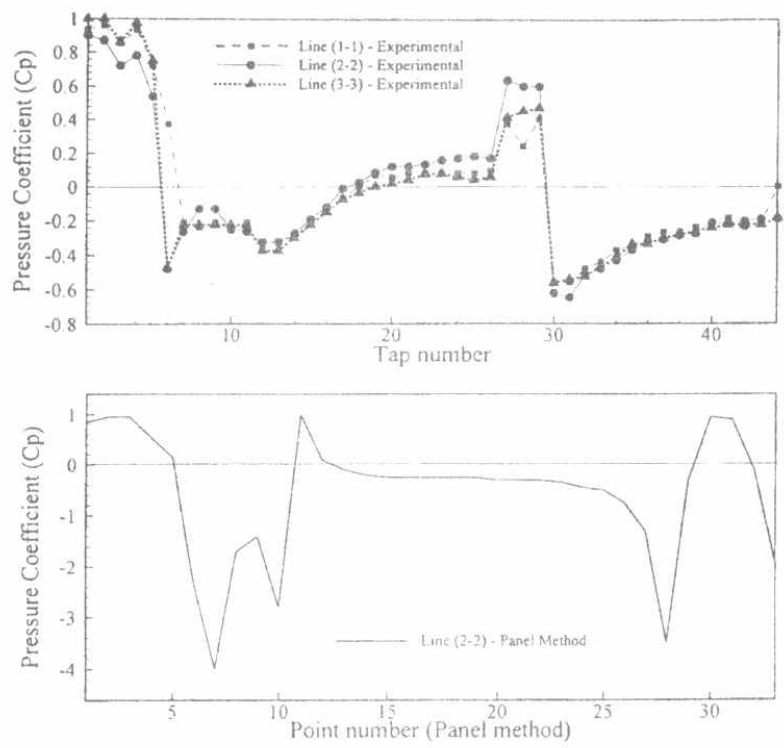

Fig. 9. The distribution of the pressure coefficient $\left(C_{p}\right)$ on the circumference of the center section of the Mercedes truck.
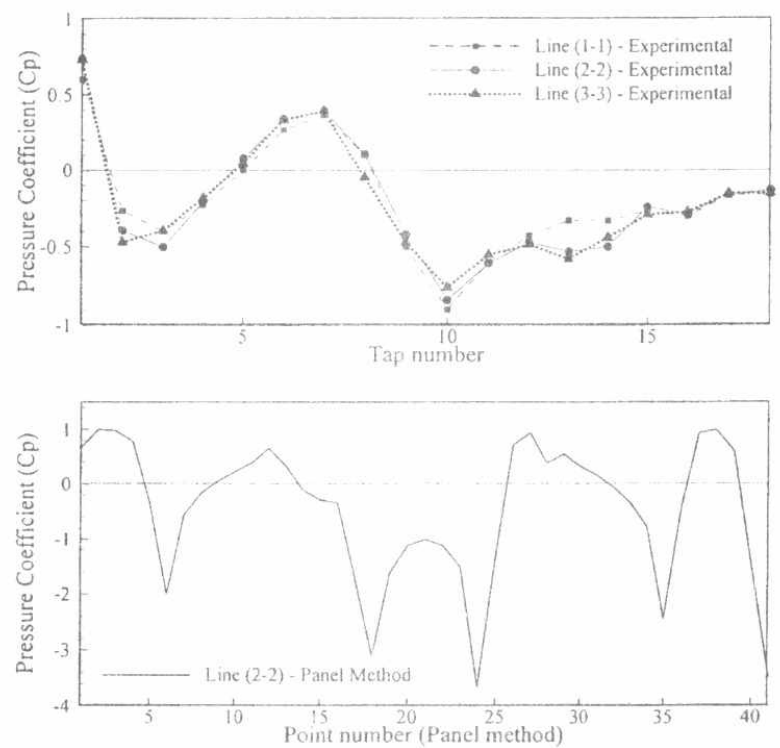

Fig. 10. The distribution of the pressure coefficient $\left(C_{p}\right)$ on the circumference of the center section of the Nissan pickup. 


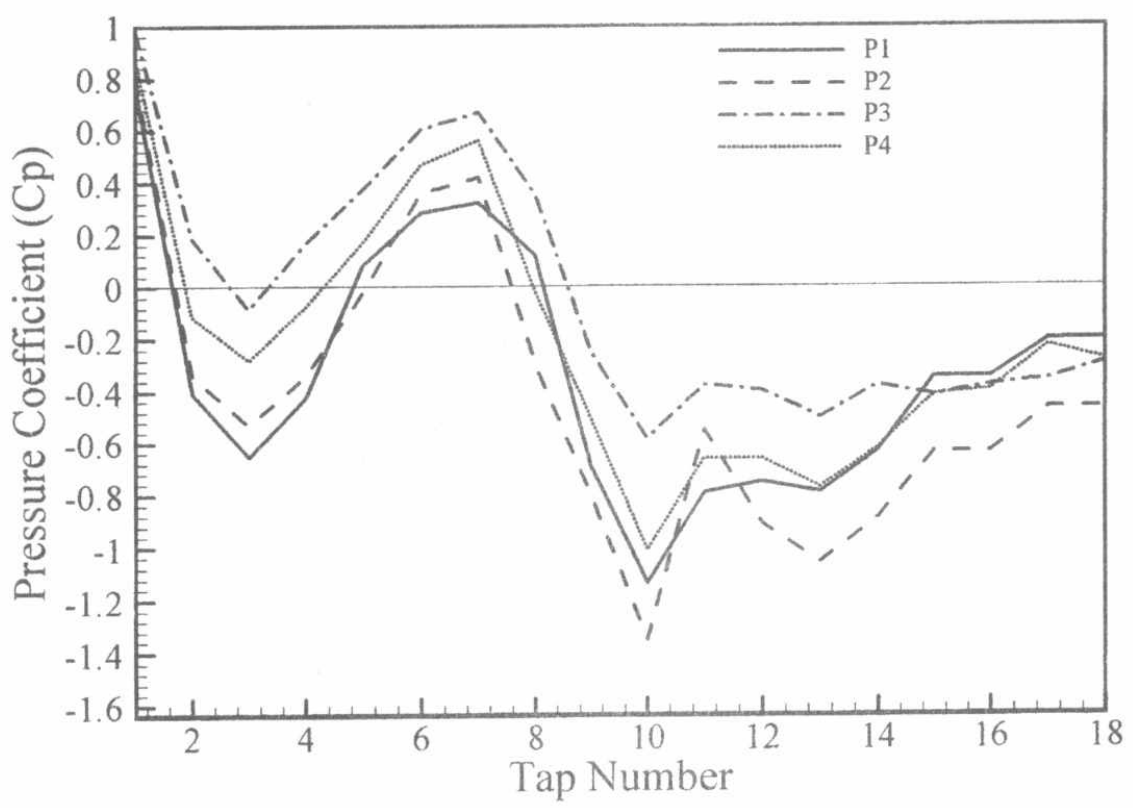

Fig. 11. The distribution of the pressure coefficient $\left(C_{p}\right)$ on the centerline of the Nissan pickup for different interference positions.

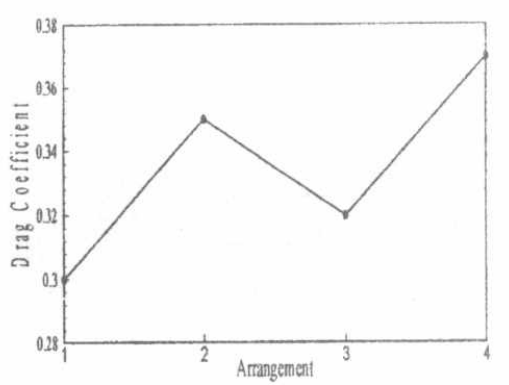

Fig. 12. The relation between the drag coefficient $\left(C_{D}\right)$ and the different overtaking arrangements of the Hyundai semi-trailer and the Nissan pickup.

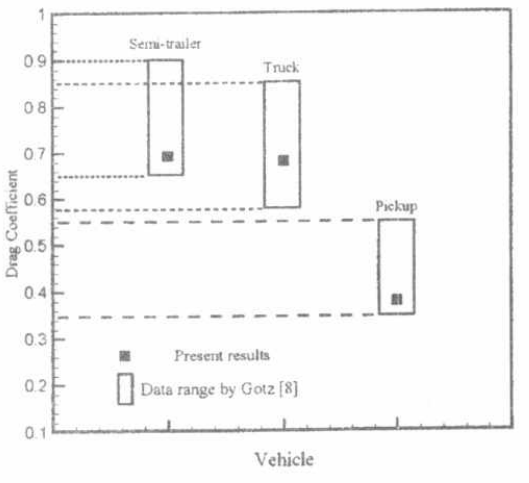

Fig. 13. Comparison between the present results and data of GÖtz [8] for the drag coefficient of the three tested vehicles. 


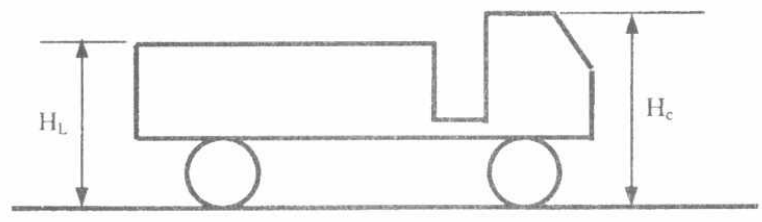

Fig. 14. The heights of both the load and cab of the truck.

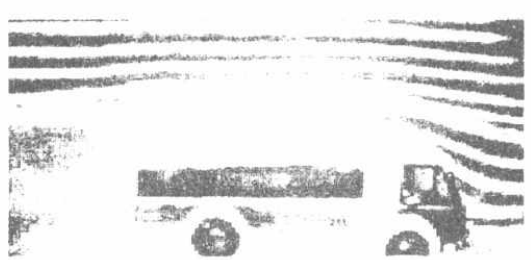

Fig. 15. Side view of the truck - the load is lower than the cab $\left(H_{L} / H_{C}=0.92\right)$

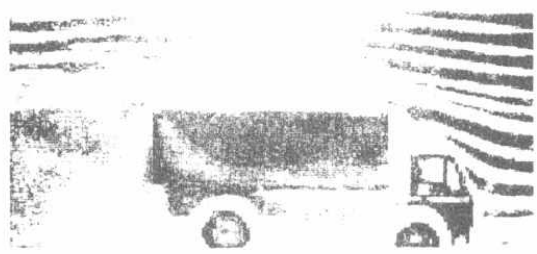

Fig. 16. Side view of the truck - the load is higher than the cab $\left(H_{L} / H_{C}=1.24\right)$, without a deflector

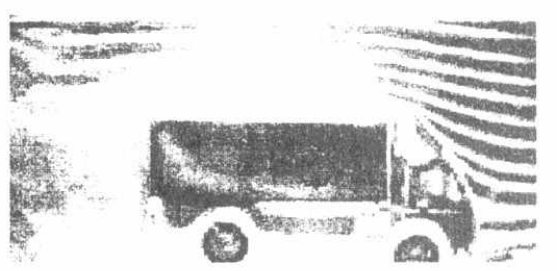

(a) with a riat defiector

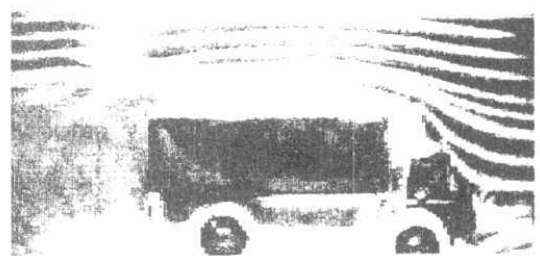

(b) with a curved deflector

Fig. 17. Side view of the truck - the load is higher than the cab $\left(H_{L} / H_{C}=1.24\right)$ 


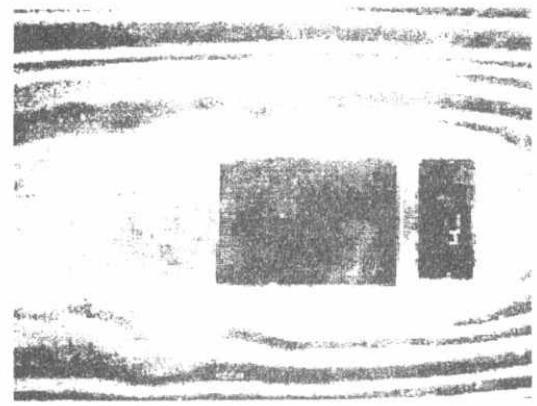

Fig. 18. Top view of the truck - the load is at the front of the truck bed $\left(H_{L} / H_{c}=0.92\right)$.

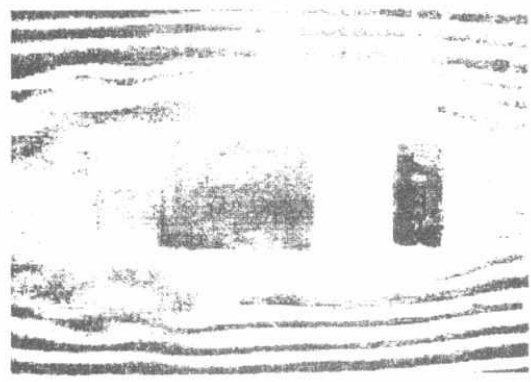

Fig. 19. Top view of the truck - the load is at the middle of the truck bed $\left(H_{L} / H_{c}=0.92\right)$

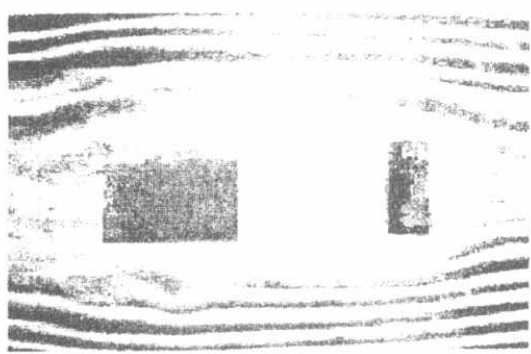

Fig. 20. Top view of the truck - the load is at the rear of the truck bed $\left(H_{L} / H_{c}=0.92\right)$. 